\title{
CHLORCYCLIZINE-INDUCED CHANGES IN THE OVARIES AND THE UTERUS OF RATS
}

\author{
Z. HRUBAN, T.-W. WONG AND E. HOPKINS \\ Department of Pathology, The University of Chicago, Chicago, Illinois 60637, U.S.A.
}

(Received 8th Fune 1972, accepted 13th Fuly 1972)

Chlorcyclizine is a substituted piperazine which is a hypocholesterolaemic and antihistaminic agent (Barnhart \& Sefranka, 1966) as well as a potent inducer of hepatic microsomal enzymes (Conney, 1967). In pregnant rats, the drug has been reported to lead to abortion and abnormal fetal development (King, Weaver \& Narrod, 1965). In two previous studies, we reported that chlorcyclizine (GZ), when fed in the diet at the level of $0.18 \%$ to male pubertal rats, is capable of producing severe damage to the testicular germinal epithelium and Leydig cells (Wong \& Hruban, 1972). In the male accessory sex glands, two types of changes are observed: those secondary to the androgen deficiency accompanying Leydig cell damage, and those due to a direct cytotoxic effect of CZ (Wong, Hruban \& Slessers, 1972). The direct cytotoxic effect consists of a peculiar cytoplasmic vacuolation of the lining epithelium of the epididymides, seminal vesicles and, to a lesser extent, the coagulating glands. Ultrastructurally, the cytoplasmic vacuoles correspond to massive accumulations of multicentric myeloid bodies. The purpose of this report is to describe the light- and electron-microscopic changes induced by $0.18 \%$ dietary $\mathrm{CZ}$ in the genital tract of female pubertal rats.

The animals used were female Sprague-Dawley rats which were 43 days old at the start of the experiment. They were allowed unrestricted access to one of the following diets: (1) chow, (2) $0.18 \% \mathrm{CZ}$, and (3) $0.18 \% \mathrm{CZ}$ followed by recovery on chow (Table 1). For the first two groups, a predetermined number of animals was killed at weekly intervals from Week 3 to Week 6 after the diets were begun. For the third group, the animals were killed after 3 weeks of CZ diet plus 3 weeks of recovery on chow. The animals were killed by exsanguination through a transverse cut in the abdominal aorta under ether anaesthesia. The tissues taken for histological examination included the ovaries, Fallopian tubes, uterus, vagina and pituitary, among others. The ovaries and the small coils of the Fallopian tubes were separated from the uterine horns and weighed. The uterus and the attached vagina (collectively labelled the uterine complex) were weighed en bloc. All tissues for light microscopy were fixed in buffered formalin, embedded in paraffin wax, cut at $6 \mu \mathrm{m}$ and stained with haematoxylin and eosin.

Samples of five corpora lutea and of uterine mucosa from a control rat and from a rat treated for 6 weeks with $\mathrm{CZ}$ were fixed at $5^{\circ} \mathrm{C}$ for $2 \mathrm{hr}$ in $1 \%$ osmium tetroxide buffered with s-collidine at $\mathrm{pH} 7.4$ and embedded in Epon. 


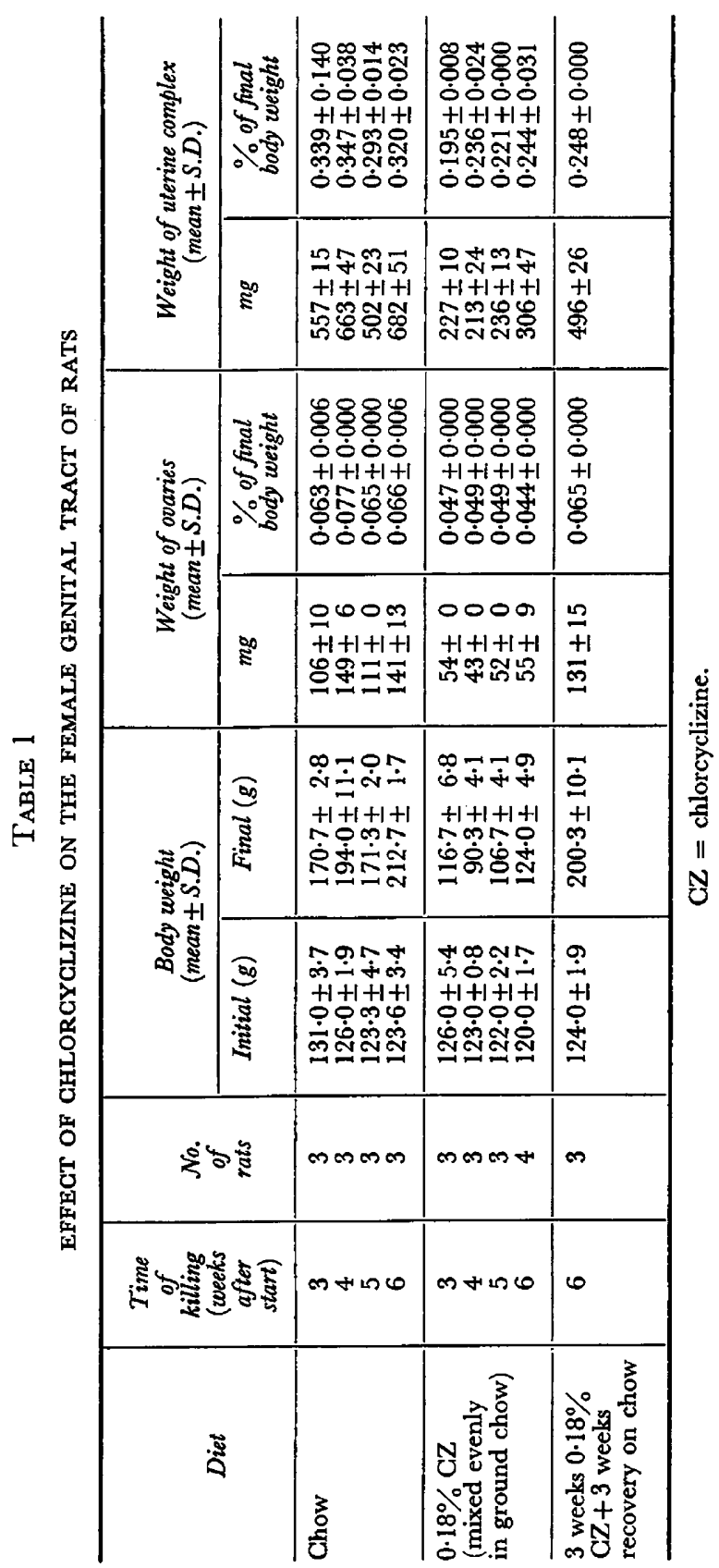


Sections stained with uranyl acetate and with lead citrate were examined with a Siemens Elmiskop 1A.

Microscopic examination of CZ-treated rats showed a generalized atrophy affecting the mucosa of the uterus and the Fallopian tubes. The most striking changes, however, were found in the corpora lutea of the ovaries. The individual luteal cells appeared abnormally lipid-laden compared to the controls. On staining with haematoxylin-eosin, their cytoplasm was unusually pale and had a finely vacuolated appearance (compare Pl. 1, Fig. 2 with a control shown in Fig. 1). Thin sections stained with toluidine-blue showed the cytoplasmic vacuoles to be densely populated with blue particles, which corresponded to myeloid bodies ultrastructurally. Such excessive cytoplasmic vacuolation affected the newly formed corpora lutea on the surface of the ovary as well as the older ones situated more deeply within the ovary. The cytoplasmic vacuolation of the luteal cells became more striking with continued feeding of $\mathrm{CZ}$ and was observed in all the animals in the experiment. Feeding of CZ for 3 weeks followed by recovery on chow for 3 weeks led to disappearance of the cytoplasmic vacuolation. Since examination of the pituitary did not reveal any obvious injury, it was assumed that the changes observed in the ovaries and the uterine complex were not the consequences of pituitary damage.

The principal ultrastructural alteration observed in the cells of CZ-treated rats was the formation of myeloid bodies. The uterine mucosal cells contained myeloid bodies with concentrically arranged membranes. While some myeloid bodies were unicentric, multicentric myeloid bodies predominated (Pl. 1, Fig. 3). Myeloid bodies were found in all portions of the cells but were particularly large and numerous in the supranuclear regions. Unicentric myeloid bodies were frequently located in the vicinity of the Golgi complex. Other alterations seen in the epithelial cells were dilatation of rough cisternae and an increased number of small fat droplets. Autophagic vacuoles were occasionally seen. Smooth muscle cells, fibroblasts and endothelial cells of the uterine wall contained a moderate number of unicentric and reticular myeloid bodies.

Myeloid bodies were numerous in the five corpora lutea obtained from a CZ-treated rat. Reticular myeloid bodies were most abundant, myeloid bodies with crystalloid patterns were less common, and unicentric myeloid bodies were rare. Reticular myeloid bodies (Pl. 2, Fig. 4) ranged from 0.6 to 2.9 $\mu \mathrm{m}$ in diameter. In one corpus luteum, however, they were up to $7.4 \mu \mathrm{m}$ in diameter and contained an occasional lipid droplet in their centre. The crystalloid myeloid bodies were 0.7 to $1.3 \mu \mathrm{m}$ in diameter (Pl. 2, Fig. 6) and frequently had an electron-lucid halo under their limiting membrane. Some crystalloid myeloid bodies were seen within autophagic vacuoles and within heterogeneous dense bodies. Several cells contained atypical myeloid bodies 4.5 to $9.0 \mu \mathrm{m}$ in diameter filled with layered membranes and reticular structures (Pl. 2, Figs 4 and 5).

Conglomerates of tubular smooth endoplasmic reticulum were seen both in control (Pl. 2, Fig. 8) and treated (Pl. 2, Fig. 6) corpora lutea. In control rats, such conglomerates were 0.3 to $0.9 \mu \mathrm{m}$ in diameter and were formed by branching tubules 25 to $50 \mathrm{~nm}$ in diameter. In treated rats, these conglomerates were larger, reaching up to $2 \mu \mathrm{m}$ in diameter. The tubules were also 
more densely packed and more extensively anastomosing, giving the conglomerates a reticular appearance (Pl. 2, Fig. 6, arrowhead). The diameters of the tubules varied but, in general, were smaller than those seen in control rats (Pl. 2, Fig. 6a).

While dynamic interpretations based on static observations are by nature speculative, we are of the opinion that the myeloid bodies in CZ-treated corpora lutea form as follows: the conglomerate of smooth endoplasmic reticulum becomes hyperplastic and its tubules form extensive anastomoses (compare Pl. 2, Fig. 8 and Fig. 6 arrowhead); decrease of the tubular lumina and of the intertubular spaces then leads to condensation of the entire structure, which is subsequently sequestered in an autophagic vacuole to form a myeloid body (Pl. 2, Fig. 4). Further condensation and rearrangement of membranes lead to the appearance of crystalloid patterns (Pl. 2, Fig. 7). The sequestered membranes are degraded at their periphery, as suggested by the halo beneath the limiting membrane (Pl. 2, Fig. 6c). Some crystalloid myeloid bodies may fuse with heterogeneous dense bodies or become doubly sequestered.

In general, myeloid bodies are specific forms of lysosomes and represent a cellular reaction to injury (Hruban, Slesers \& Hopkins, 1972). Unicentric and multicentric myeloid bodies have been induced by a variety of drugs in many different tissues (Read \& Bay, 1971; Hruban et al., 1972), but crystalloid myeloid bodies are seen only in certain cell types, such as Leydig cells, adrenal cortex, neurons and smooth muscle (Chen \& Yates, 1967; Yates, Arai \& Rappoport, 1967; Schutta \& Neville, 1968; Dietert \& Scallen, 1969; Russo, 1971). It is possible that the membranes of endoplasmic reticulum in these cell types possess certain structural attributes which are most favourable to a crystalloid reorganization following sequestration.

Supported by Grants CA- 05310 and CA-12854 from the National Gancer Institute, and Grant HD-06477 from the National Institute of Child Health and Human Development, National Institutes of Health. Dr Wong was a Special Fellow of the United States Public Health Service (F3-CA-23, 101) during the major portion of this investigation. Dr Hruban is a Research Career Development Awardee of the United States Public Health Service (5 K03 A07161). The chlorcyclizine (as hydrochloride) was kindly provided by $\mathrm{Dr}$ G. H. Hitchings of Burroughs-Wellcome \& Co., Inc.

\section{REFERENCES}

Barnhart, J. W. \& Sefranka, J. A. (1966) Hypocholesterolemic activity of anti-histaminics. Life Sci. $5,871$.

\section{EXPLANATION OF PLATE 1}

Frg. 1. Normal corpus luteum from a control rat on chow, killed 5 weeks after the start of the experiment. Haematoxylin-eosin, $\times 500$.

Fig. 2. Corpus luteum from a rat on $0 \cdot 18 \% \mathrm{CZ}$ for 5 weeks. The luteal cells have markedly lipid-laden cytoplasm which is finely vacuolated. Haematoxylin-eosin, $\times 500$.

FIg. 3. Portions of several cells from the uterine mucosa of a rat treated with $\mathrm{CZ}$ for 6 weeks. Several unicentric and many multicentric myeloid bodies are seen. $\times 8700$. 
PIATE
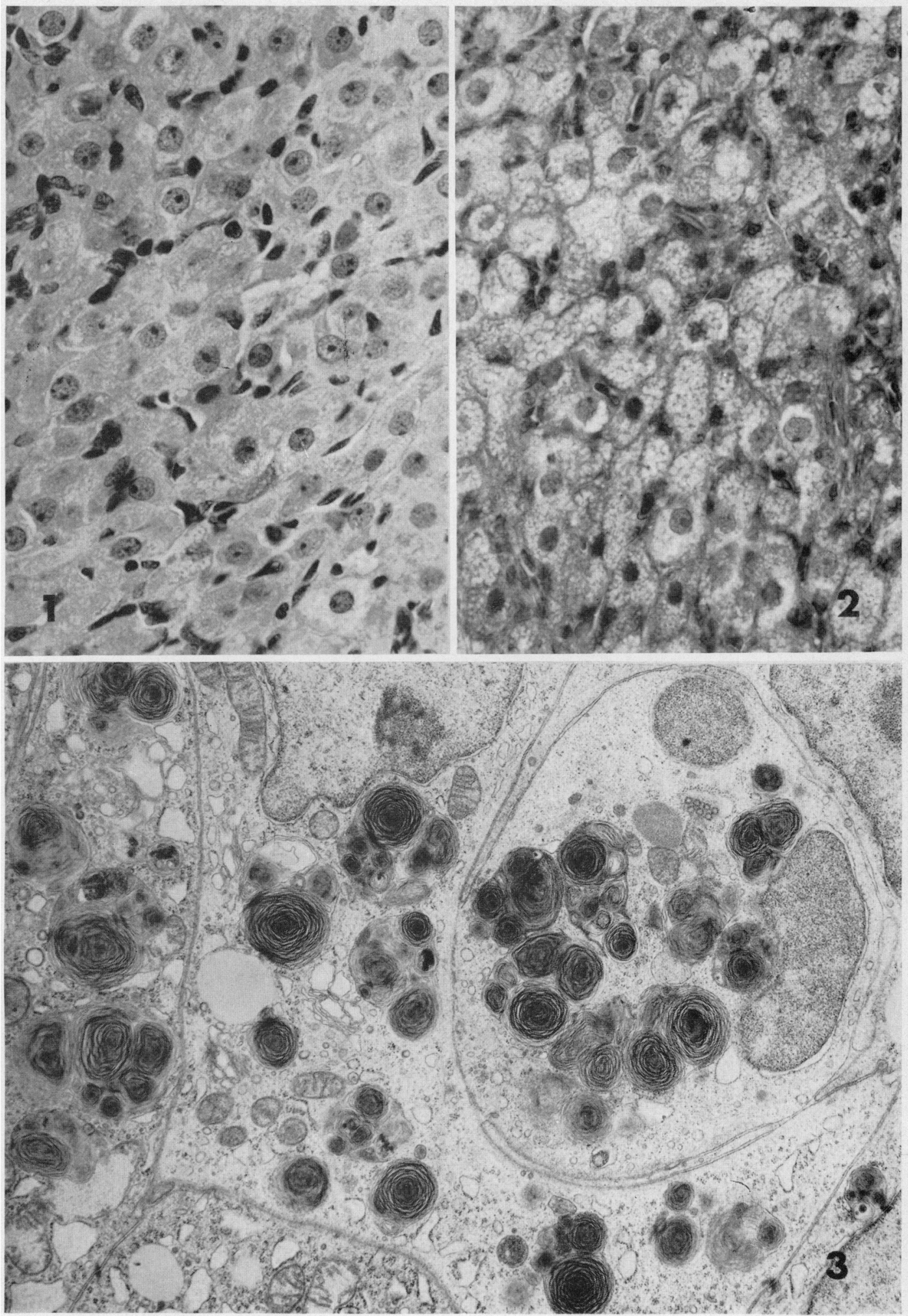


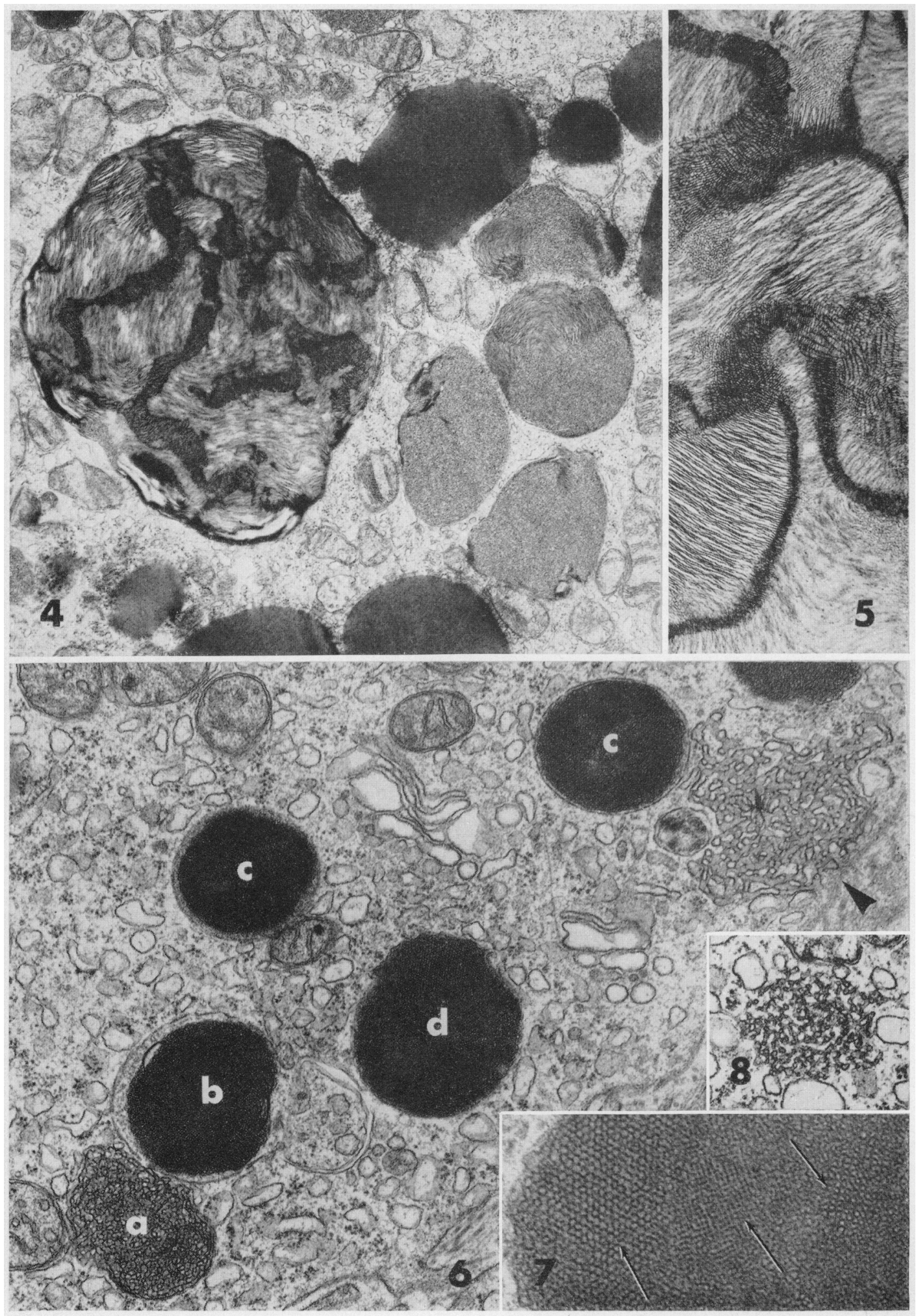


Chen, I. L. \& YATEs, R. D. (1967) An ultrastructural study of opaque cytoplasmic inclusions induced by triparanol treatment. Am. F. Anat. 121, 705.

Conney, A. H. (1967) Pharmacological implications of microsomal enzyme induction. Pharmac. Rev. $19,317$.

Dietert, S. E. \& Scallen, T. J (1969) An ultrastructural and biochemical study of the effects of three inhibitors of cholesterol biosynthesis upon murine adrenal gland and testis-histochemical evidence for a lysosome response. F. Cell Biol. 40, 44.

Hruban, Z., Slesers, A. \& Hopkins, E. (1972) Drug-induced and naturally occurring myeloid bodies. Lab. Invest. 27, 62.

King, C. T. G., Wraver, S. A. \& Narrod, S. A. (1965) Antihistamines and teratogenicity in the rat. 7. Pharmac. exp. Ther. 147, 391.

READ, W. K. \& BAY, W. W. (1971) Basic cellular lesion in chloroquine toxicity. Lab. Invest. 24, 246.

Russo, J. (1971) Combined effect of triparanol and human chorionic gonodotrophin on the ultrastructure of the adult Leydig cell. Z. Zellforsch. microsk. Anat. 113, 249.

Schutta, H. S. \& Neville, H. E. (1968) Effects of cholesterol synthesis inhibitors on the nervous system. Lab. Invest. 19, 487.

Wong, T.-W. \& Hruban, Z. (1972) Testicular degeneration and necrosis induced by chlorcyclizine. Lab. Invest. 26, 278.

Wong, T.-W., Hruban, Z. \& Slesers, A. (1972) Chlorcyclizine-induced changes in the epididymides and the prostatic complex of rats. Biol. Reprod. (in press).

Yates, R. D., ARAI, K. \& Rappoport, D. A. (1967) Fine structure and chemical composition of crystalline cytoplasmic bodies of triparanol treated Syrian hamsters. Expl Cell Res. 47, 459.

\section{EXPLANATION OF PLATE 2}

FIG. 4. Portion of a cell from the corpus luteum of a CZ-treated rat. On the right are myeloid bodies with reticular content. On the left is a large myeloid body with reticular and layered membranes. The dense structures are lipid droplets. $\times 12,400$.

Fig. 5. Portion of a large myeloid body with layered and reticular membranes. $\times 24,000$. Fig. 6. Portion of a cell from the corpus luteum of a CZ-treated rat. A conglomerate of smooth endoplasmic reticulum is seen at the arrowhead. Condensed conglomerate (a), a myeloid body with a crystalloid content in an autophagic vacuole (b), and two myeloid bodies with crystalloid content and a lighter zone under the limiting membrane (c) may represent stages in myeloid body formation. The crystalloid content of one myeloid body (d) is enlarged in Fig. 7. $\times 22,400$.

Fig. 7. Portion of a crystalloid myeloid body showing several internal structural patterns (arrows). $\times 64,000$.

FIc. 8. A conglomerate of smooth endoplasmic reticulum from a luteal cell of a control rat. Compare with Fig. $6 \times 26,400$. 